\title{
Gender/Minority Projection
}

National Cancer Institute

\section{Source}

National Cancer Institute. Gender/Minority Projection. NCI Thesaurus. Code C19593.

An estimate of the percent of each sex will exits for a minority. 